\title{
The Impact of CPD in Teaching, and the Role of Principal in Promoting CPD:
}

\author{
A Literature Review
}

\author{
Cecep Somantri ${ }^{1,2, *}$, Harris Iskandar ${ }^{2}$ \\ ${ }^{1}$ School of Education \\ ${ }^{1}$ The University of Nottingham, ${ }^{2}$ The Ministry of Education and Culture Republic of Indonesia \\ ${ }^{1}$ Nottingham, United Kingdom, ${ }^{2}$ Jakarta, Indonesia \\ *cecep.Somantri@nottingham.ac.uk
}

\begin{abstract}
Continuing Professional Development (CPD) has increasingly been seen as a fundamental element of learning, teaching and education worldwide. However, the concept of CPD lacks clarity in terms of how it is defined, as well as in its goals. This paper focuses specifically on the role of school principals in developing school and learning amongst teachers; discussing and outlining the principals' duties with regards to teachers' development; the way in which the principals' work is influenced, teachers' expansion and development, and the outcomes within the school setting. Carried out as a desk-based research that reviews extensive literature and empirical research from the last three decades, this paper concludes that CPD is not simply a form of teacher training, but a more holistic type of lifelong learning. CPD is an ongoing duty, embedded in the roles of both principals and teachers as educators, rather than a standalone programme or activity. Teachers are to be held accountable for their own development and must look to principals for guidance without depending on them completely.
\end{abstract}

Keywords-continuing professional development, CPD, school leadership

\section{INTRODUCTION}

Professional development is crucial in ensuring that teaching and learning standards are upheld and improved in the school setting [1-3]. The importance of professional development in school development and change is also evidenced by numerous examples of research around the globe [4,5]. The literature demonstrates that: (i) classrooms and schools are able to achieve the highest standards when teachers are given the opportunity to learn new information and share their experiences with others; (ii) schools eager to develop are focused on teacher development and information-sharing; and (iii) students' own performance and learning can be influenced significantly by what teachers themselves are able to learn. Joyce et al. [6] explain that this is because students are better able to access greater learning opportunities when their teachers have clear goals and apply a range of effective teaching tools and techniques. Furthermore, Talbert and McLaughlin [7] found that along with improving teacher- student relationships and teachers' dedication to the role, professional development also has an important influence on pedagogy and the curriculum.

Reports such as those published by Maden and Hillman [8], Gray [9], OFSTED [10] and Harris [3] emphasise that schools' ability to improve and develop depends greatly on different factors, such as the determination to improve teaching quality, highlighting teacher development, and ensuring that staff collaborate well with one another. These reports also note that teachers must participate in ongoing development at both the personal and professional levels throughout the course of their careers, with a focus on meeting their own specific needs. These needs will depend on their outlook and perspective, work experience, personal experience, present situation, and so on. The research also asserts that learning can only be achieved and result in positive outcomes in the classroom and school if the teachers' developmental needs are in line with the development programme or task being undertaken. In this context, Day [11] notes that development initiatives are of minimal benefit to students and teachers when they have no clear relevance to the real-life classroom, when they are badly designed, and when they do not meet the needs of the specific staff member involved in the development activity. The literature also demonstrates the importance of focusing on creative, innovative and curious participation in professional development activities if students and teachers are to realise greater achievements in learning and teaching, respectively. Little [12] and Joyce et al. [6] support this point, noting that both teaching and learning have been shown to improve through opportunities such as sabbaticals, mentoring and coaching between peers.

In this paper, it is highlighted that the concept of CPD lacks clarity in terms of how it is defined, as well as in its goals. It specifically focuses on the role of school principals in school development and learning amongst teachers; discussing and outlining the principal's duties with regards to teachers' development, the way in which the principal's work is influenced, teachers' expansion and development, and the outcomes within the school setting. This paper concludes with 
consideration of an effective CPD plan capable of positively impacting the performance of both students and teachers.

\section{DEFINING CPD}

Hargreaves [5] and Bolam [13] indicate that school performance depends greatly on professional development. However, as noted earlier, there is a great deal of ambiguity surrounding the concept of professional development itself [14], resulting in much debate and a lack of clarity [15]. Friedman et al. [16] summarise the British literature, reporting definitions that span anywhere from a way to achieve personal development or a form of learning that spans the professional's lifetime to a way for professionals to gain security and control in the turbulent contemporary workplace environment. Other definitions include professional development being a way to reassure others that professionals have the latest technological training, a way for professional associations to demonstrate compliance to professional standards, and a way for employers to ensure that they employ flexible, capable, well-qualified staff.

This being said, Friedman et al. [16] note that $40 \%$ of professional associations in the UK use the definition provided by the Construction Industry Council (CIC). Researchers such as Tomlinson [17], Rapkins [18] and Kennie [19] also note the prevalence of this particular definition in the research. The CIC's definition is as follows:

$C P D$ is the systematic maintenance, improvement and broadening of knowledge and skill and the development of personal qualities necessary for the execution of professional and technical duties throughout the practitioner's working life.

Whilst the CIC's definition considers personal, professional and technical attributes of the individual, Friedman et al. [16] highlight that the definition of CPD used by most associations differ from the above definition. These definitions also vary greatly from one another, with different associations perceiving CPD as a mode of, activity in or approach to learning and/or education. The variance in definitions is further highlighted in the literature, as shown below:

It can sometimes seem that there are as many definitions of $C P D$ as there are professional institutions encouraging their members to participate in it. We all think that we know what the words 'continuing', 'professional' and 'development' mean until we come to define them [20].

On the other hand, the following definition of CPD considers any behaviour designed to create change at the classroom level:

Professional development consists of all-natural learning experiences and those conscious and planned activities which are intended to be of direct or indirect benefit to the individual, group or school, which contribute, through these, to the quality of education in the classroom. It is the process by which, alone and with others, teachers review, renew and extend their commitment as change agents to the moral purpose of teaching; and by which they acquire and develop critically the knowledge, skills and emotional intelligence essential to good professional thinking, planning and practice with children, young people and colleagues throughout each phase of their teaching lives. [11].

\section{CPD AND SCHOOL IMPROVEMENT}

It has been proposed that when CPD is carried out with consideration of the school's, students' and teachers' needs, benefits can be seen across all three interconnected areas [21]. One of the key components of CPD is evaluation and assessment, which both facilitate the identification of requirements and needs regarding $\mathrm{CPD}$, whilst also highlighting how effective the development process has been [22]. Knight [23] asserts that if teachers are to properly learn and reflect on their teaching methods, they must be able to access and utilise both statistical and in-depth information. However, Edmonds and Lee [24] also note that evaluating the learning outcomes that arise for students as a result of CPD is more complicated than it is to evaluate the outcomes for teachers. McAteer et al. [25] further explain that teachers have been shown to face challenges when attempting to pinpoint the outcomes of CPD and to demonstrate the link between student performance and teaching practice. Furthermore, the researchers add that teachers are often unable to determine whether their teaching methods transformed as a result of their engagement with CPD or whether they engaged in CPD because they were committed to transforming their approach to teaching.

Edmonds and Lee [24] argue that it is more difficult to assess the ways in which CPD affects students' learning, and comparatively easy to determine how CPD affects teaching practice. Solid data demonstrating a clear cause-and-effect between CPD and increased student attainment are indeed difficult to come by, with assessments typically made based on personal feeling or reflection rather than objective evaluation. This being said, Cordingley et al. [26] note that teachers become more eager to participate in CPD when they are able to recognise the benefits it can bring. Therefore, it is essential that teachers are made aware of the positive outcomes that CPD can create.

These benefits can be seen across a broad range of areas, from professional awareness, values, emotional state, motivation, knowledge and skills to resources, information, teaching practice and school performance. CPD can improve the resources, tools and materials used by teachers whilst also informing them of changes in policy, new initiatives, facts and information. Teachers involved in CPD can experience an internal transformation of their value systems, ideas, and way of thinking, whilst also finding themselves growing more aligned with the approaches and values embodied within CPD itself. Emotionally, teachers who participate in CPD often experience a shift in feeling towards teaching and whilst they could experience feelings of demoralisation, they can also find themselves operating with a new sense of confidence and 
commitment in their ability to teach and create change, for instance. Participation in CPD also allows teachers to sharpen their critical thinking skills, adopt a more flexible approach to teaching, and become more aware and knowledgeable about teaching and the curriculum. At the school level, CPD can improve the level of mutual support between staff whilst also improve agreement and teamwork. Finally, CPD can also help to create greater focus on student performance and outcomes given that improving students' learning is the main goal of CPD overall [2].

Whilst the above outcomes are broad and varied, other researchers have proposed that CPD benefits can be expressed in a more straightforward way [27], with four main outcomes: awareness; concepts and organised knowledge; principles and skills; and application and problem solving. Respectively, these outcomes bring teachers greater acknowledgement of the significance of their CPD area, understanding in terms of how knowledge is gained, possession of the tools required to effectively teach students, and applying their own skills to their real-world teaching practice. These researchers propose that teachers should engage in CPD with a view to focusing on each one of these outcomes in turn, moving on to the next stage once they have achieved the one prior to it. However, Harland and Kinder's [2] aforementioned framework takes a broader perspective with regards to $\mathrm{CPD}$ and is therefore in disagreement with Joyce and Showers' approach.

In other work, a five-part hierarchical model has been proposed with regards to CPD outcomes [28]. Here, it is asserted that the most effective way to evaluate the impact that CPD has had on teachers is to interview teachers themselves or to invite them to focus groups to gain feedback. In taking this approach rather than a quantitative alternative such as a survey, CPD participants are able to provide more in-depth feedback about outcomes and causality from their own perspectives. Guskey [28] also recognises the difficulties involved in assessing learning outcomes amongst teachers, but suggests that one way to achieve insight would be to carry out questionnaires both before and after teachers' participation in CPD. Guskey asserts that the ability of CPD programmes to create genuine change increases when the school is in favour of CPD, and suggests that extensive case studies can be useful in measuring both the degree of change and support that can be observed at the school level. Additionally, Guskey proposes that longitudinal observation can be used to assess teachers' application of the skills and information they have acquired as a result of CPD. This being said, these measures require investment in observer training whilst also necessitating that observations are carried out numerous times over an extended period as well as the way in which teachers respond to the prospect of being observed in lesson. Additionally, as recognised, it is notoriously challenging yet essential to find a way to assess impacts on students' learning.

Teachers seem to be able to share their perspectives on how CPD influences attitudes and feelings even if they find it difficult to pinpoint how CPD impacts students' performance or learning. The literature notes that teachers' feedback on outcomes includes positive outcomes such as less hesitation about being observed in the classroom, greater interest in teamwork and partnership, embracement of change and innovation, greater self-efficacy, better motivation and higher confidence $[29,30]$. It has been proposed that the effectiveness of CPD can be measured in terms of teachers' motivation and enthusiasm following participation in CPD [2], which is supported in other work, wherein teachers reported that they considered CPD to be a success if it led them to feel more enthusiastic and confident in their practice [24]

Researchers such as Burchell et al. [31], Lyle [32] and McAteer et al. [25] have reported positive outcomes ranging from greater feelings of fulfilment, ability to secure promotion, better teamwork between teachers, higher engagement in applying best practice, better problem-solving, enhanced dialogue, improved critical thinking and professional reflection, and teachers taking a more proactive and active role in their teaching practice. The researchers also note that teachers who had engaged in CPD were more eager to engage in lifelong learning and to reconnect with their passion for teaching. Teachers have also reported other positive outcomes of CPD such as greater critical thinking with regards to teaching, greater interest in challenging the status quo, and having the opportunity to think in new ways. This focus on change and innovation is particularly noted in postgraduate education research. McAteer et al. [25] also highlight the ways in which both teaching and learning can be influenced by the points noted above, with outcomes such as greater knowledge and skills, development of the curriculum, student-centred practice, and greater engagement in leading and training.

Whilst a small portion of the literature does focus on the impact on students, this tends to be less focused on academic performance and more focused on how CPD has influenced students' behaviours, attitudes and feelings. It has been proposed that teaching may be improved to a more significant degree if CPD is performed with a primary focus on supporting the student [33] but assessing student outcomes based on examination results is a complicated topic. Robison and Sebba [33] further add that other challenges arise from the fact that whilst teachers who participate in CPD need time to implement what they have learned in the classroom; it takes even longer for this to cause a measurable impact on students' performance. The researchers also point out that since this can take a significant length of time, it is difficult to determine whether changes in students' performance are the result of their teachers' participation in CPD or the result of other interventions.

In a study, students provided feedback regarding their perceptions of the impacts of their teachers' involvement in CPD, noting that they felt more motivated, enthusiastic, confident, organised and involved in class, whilst also achieving better grades and feeling that their self-esteem had improved [29]. On the other hand, McAteer et al. [25] note that teachers have reported outcomes such greater understanding between themselves and students as well as noting that students 
appear to be keener to engage in lessons, demonstrate a more positive attitude, and behave better in class.

\section{The Role of the PRINCIPAL In TEACHERS' PROFESSIONAL DEVELOPMENT}

The school principal can have a major impact on the effectiveness of CPD and its application in practice, being largely responsible for ensuring that all members of the school are able to work and learn in a supportive environment. Principals have been seen to impact learning amongst teachers in four main ways: through instructional leadership and learning; by building an institutional environment that supports learning; by actively participating in the creation and distribution of CPD material and programmes; and by effectively evaluating CPD outcomes [34]. These points are now expanded below.

\section{A. Instructional Leadership}

Principals can facilitate and embrace learning in a number of different ways, from day-to-day contact with staff and pupils, giving praise and rewards, creating events for the first day of term, creating achievement boards, adopting symbols and school mottos, and so on. All of these activities and measures place value on learning as a key focus of the school and every individual who works and learns there. Principles must themselves ensure that they facilitate the realisation of the desired outcomes through emphasis on resources and specific needs with regards to training programmes and other incentives. This is essential since all change requires investment, both in terms of time and resources [35]. Principals must take responsibility for facilitating change through coaching, mentoring, support, modelling and sharing feedback. They must encourage positivity and enthusiasm about learning, drive change, and champion the positive impacts that can be seen at both the school level and in terms of students' learning outcomes. This helps teachers to cope with the difficulties associated with change and transformation. It is also essential that principals are there to assist teachers in managing these difficulties and tackling problems head-on

\section{B. Creating A Learning Environment: Communication, Support And Management}

In order to develop and improve teachers' professional practice continually, it is crucial to create a supportive environment, which is the second area where principals play a considerable role in teachers' learning and development in schools.

1) Communication: Bredeson [36], Gronn [37] and Hart and Bredeson [38] demonstrate that one of the main mechanisms through which principals have an impact is communication. Principals effectively take a steering role in promoting the relationship between learning amongst teachers and learning amongst students. With effective communication, principals are therefore able to empower their staff, teachers and students to achieve positive change. Listening is also an essential part of communication. Therefore, principals who wish to foster a learning culture within their school must be able to recognise the skills, knowledge and experiences of the school's members. This also grants teachers the ability to more actively participate in their own development, lending teachers greater decision-making power, which enhances the quality of learning and teaching achieved within the school and develops collective leadership.

2) Support: Along with their role as a communicator, principals are also key supporters of transformation and learning amongst teachers, providing the necessary support in the form of budgets, funding, tuition fees and materials whilst also facilitating development activities such as travel and seminars. Principals can also lend support by providing teachers with the opportunity to be challenged and step out of their comfort zone, encouraging creative problem-solving, innovation and change. It is growth - not perfection - that is at the core of teaching. It is essential that teachers feel they have the principal's support on all levels, particularly during difficulties. Principals must also serve as role models, sharing their experiences, skills and knowledge. This may be in the form of sharing information about updates to policy or legislation, providing encouragement and motivation, sharing knowledge about learning and teaching, communicating areas of change within the school, discussing ways to utilise modern technology to improve teaching and learning, facilitating team development, and so on.

3) Management: An essential aspect of the principal's work is the variety of management tasks. In order to frame a successful and sustainable learning environment, hard work and efficient management are required. Thus the following tasks are included: recruit and hire teachers who are as learners; coordinate continuing professional development process; make decisions which is related to school resources as well as priorities; for purpose of working and learning together, principal should manage time, space and opportunities for teachers; identify resources and provide information to staff; The integration of available incentives with the focus of continuing professional development; the placement of alternative teachers; the access to the classroom; the development and implementation of teacher assessment practices to support development and improvement; also as a buffer prevent excessive intrusions as well as weak extrinsic forces which could threaten the school learning environment. Principals who handle these administrative tasks successfully could play an important role in creating a learning environment that supports schools.

\section{Participation in Creating and Implementing CPD Materials}

The effectiveness of CPD activities is greatly supported by the active participation and involvement of teachers in creating their own development opportunities and programmes, as this 
helps to ensure that the requirements of the teachers are met. This allows for a more profound impact on teaching practices and attitudes. As leaders of the schools in which teachers work, principals play a major role in encouraging teachers to learn, develop and improve their practice proactively and independently. Therefore, principals must be involved in creating development opportunities that are able to fulfil the requirements of teachers, students, the school and the local area. In this way, principals act as a guiding force to achieving collective objectives, ensuring that all efforts are conducive to the realisation of goals, and that development activity does not become convoluted or lost in light of the bigger picture.

Principals' encouragement of teachers' active participation in autonomous learning is an important part of their role as school leaders. Today's principals must ensure that teachers are actively engaged in creative thinking and reflection as part of their professional development, and they must facilitate this wherever possible. By achieving this kind of dialogue with their staff, both teachers and principals are better able to achieve development in new, refreshing and more effective ways [39].

The needs and requirements of teachers can be most effectively met through such dialogue along with collaboration, teamwork, planning, school-level review and curriculum reform. Principals can play an important role in supporting teachers when they focus on each teacher's unique skills, experiences and needs and basing developmental opportunities on these specific factors. Teachers will look to principals for guidance in gaining clarity and purpose on their objectives, and principals can support teachers in achieving these objectives by ensuring that they hold regular, long-term performance reviews that consider not only the teacher's own progress and development, but the objectives of the school and the learning outcomes for students. Therefore, it must be highlighted that the position principals take in teachers' development is multifaceted: they work to integrate the needs of the school, the students and the teachers whilst also actively participating in the creation and implementation of development activities. In this sense, principals do not only act as supporters of staff development, but active drivers of growth and change.

\section{Evaluating CPD Outcomes}

In the majority of cases, basic satisfaction-based questionnaires are employed as the only method of evaluating the effectiveness of development initiatives, being in the minority with their use of more extensive assessment tools. It can largely be said that conventional assessment tools are unable to provide in-depth insight into how CPD improves school quality and performance, student learning outcomes, teaching practices, and teachers' beliefs and knowledge. This makes it difficult for evidence-based policy to be created. Therefore, we must ask how principals can play their part in improving the value of development evaluation. The first approach would be to ensure that teachers are frequently assessed in order to support them in gaining clarity on their personal and professional development goals. The second way in which principals can improve evaluation in the context of CPD is to embed teachers' specific needs into the development activities available to them. This involves collaboration between teachers and principals, with a focus on identifying what it is that teachers need and how this fit with the needs of the students and the school. The third area of influence in terms of improving evaluation is the creation of more effective evaluation processes.

Whilst the significance of the principal has been well established, it should also be recognised that just as teachers cannot fully determine the extent of students' learning, principals are not solely responsible for teachers' development. Instead, the role of the principal is to encourage teachers to become proactive learners; sharing their knowledge and guidance without encouraging over-dependence.

\section{CRitical Evaluation of CPD}

Although the significance of teachers CPD is broadly recognised among professions, evaluations on the effect of CPD are barely engaged in a methodical and concentrated way. Research in related CPD evaluation practices demonstrates that, on various occasions, current practice shows to be limited in lots of aspects. These disadvantages can be outlined as follows:

First, most 'evaluation' simply summarises the activities carried out as a part of the professional development plan: what kinds of courses were presented, how many credits amassed etc. This apparently does not justify the influence of these activities undertaken so that this kind of data collection is not sufficient as approaches to review the impacts of CPD.

Second, in the presence of certain evaluations, this mostly takes the way of questionnaire about participant satisfaction. Apparently, these allow the measurement participants to consider if the activity is pleasant and successful, however, this approach does not involve concern related to the acquisition of ability or the change of practice which is supposed from professional development, and assuredly does not assess if student outcomes are related to these changes

Third, evaluation is usually also simple, one-off events, usually after the event. Since the most meaningful changes are often in a long-term way, various of professional development activities would take place in a long period of time, and the evaluation needs to indicate this and happen in the same way. Evaluation also needed to be carried out in parallel with professional development activities [28].

Edmonds and Lee [24] demonstrate that, according to a study of CPD activity in England, in many cases, evaluation was based on the feedback form, which is completed by teachers, delivery and content issues are included, and if they considered course satisfaction as its objectives. Question of whether it is cost-effective and may affect teaching and learning is rarely designed. It is unusual to do the follow-up action and the real impact in teaching and learning is scarcely conducted, moreover, long-term guiding impacts are often 
absent. Teachers stated that they could feel that CPD promoted teaching and learning, yet there is no strong confirmation of impact. There is another study examines the effect of leadership development programs. Bennett and Smith [40] lead a survey suggested that only a half of participants claimed to be studying the effect of CPD. Although managers stated that various impacts have been revealed in the qualitative follow-up by in-depth interviews, there still was a considerable argument on the impact of any CPD program among the devise members of the same organisation. According to the qualitative part of study, even though one school has made any clear evaluation of the impact of professional development in schools, they are using a rather immature self-assessment method.

Harris [3] indicates positive movement with regards to schools' involvement in greater development and learning, whilst Eastwood and Louis [41] assert that this is primarily achieved through emphasis on collaboration. As researchers such as Joyce and Showers [42], Hopkins and Harris [43] and Smith [22] explain, this further highlights the need for improvement in CPD evaluation so that students' learning is effectively supported. However, the emphasis on teachers' satisfaction with CPD programmes is a noted issue in the majority of current approaches to CPD assessment [44]. Therefore, the latter researchers assert that future evaluation must focus on how well teaching practice actually aligns with the desired outcomes of teacher development activities. The specific goals and materials within any given CPD programme depend on the school in question, and potentially the government under which it is run. Rather than focusing only on teachers' satisfaction, evaluation must identify student and teacher outcomes on a behavioural level.

Thus, it is believed that the most accurate way to assess the learning outcomes of teachers is to identify how their behaviour, feelings and thoughts have changed as a result of $\mathrm{CPD}$, whilst also encouraging reflection. Of course, it is also essential that student outcomes are assessed. This will help to determine the relationship between teacher development and students' learning, behaviour, or performance. Such evaluation should also consider teachers' behavioural change along with the specific school-level support needed. Lastly, costeffectiveness should also be evaluated. This will help to determine where development activities are best delivered, amongst other factors.

\section{DESIGNING EFFECTIVE CPD}

Hopkins and Harris [43] support the argument that the desired outcomes can only be achieved if teachers' development needs are fulfilled by the programme they participate in, whilst Day [11] adds that neither students nor teachers benefit greatly from development activities that are largely irrelevant to practice, that do not fulfil participants' needs, and are not well-planned. Jones and Fear [45] also assert that CPD programmes must be in line with the objectives of the teachers and the school, although it should be pointed out that party's needs may take precedence at certain points in time.
Therefore, Day [46] argues that the needs of both schools and teachers must be evaluated.

Six core points have been raised in the literature [47] regarding professional development. Firstly, change is the responsibility of both schools and teachers, and development activities should be oriented towards classroom practice whilst also being compatible with the school's values and resources. Secondly, success is most likely to be realised when small changes are gradually made. Thirdly, whilst collaboration can help individuals to accept change, teams should be small to maintain focus and action. Fourthly, feedback channels must be put in place, particularly in order to communicate positive change. Positive attitudes and perceptions often lead to positive behaviours and outcomes. Additionally, teachers should be supported in implemented change, whilst also being challenged and kept accountable, particularly when first enacting the skills and knowledge learned. Teachers will naturally implement these principles over time. Finally, in order to ensure that too much change does not happen at once, new programmes should be compatible with programmes that are already in place, and ideally implemented as part of these practices.

This being said, CPD effectiveness will depend on the specific situation [47], and the needs of the school should be considered alongside the teacher's position in their professional and personal life [46].

\section{CONCLUSION}

Continuing professional development (CPD) is progressively seen as crucial for all professionals to preserve and evolve their capabilities. CPD is broadly recognised to significantly contribute to teachers' professional and personal development, while playing an important role in the life of schools, which can improve teaching and learning.

Teachers' ability to steer students towards optimal learning opportunities greatly depends on their own development and growth. CPD is therefore a crucial element of learning, teaching and education. However, the lack of clarity surrounding the definition of CPD has been highlighted, and it must be understood that CPD is not simply a form of teacher training, but a more holistic type of lifelong learning. The literature indicates that the way students perceive their own learning and performance, as well as the methods used by their teachers, can be influenced by teachers' own development. Teachers who are clear on their teaching style and goals, and who are motivated both intrinsically and extrinsically, are more likely to apply rich, varied methods. These teachers are also found to demonstrate higher satisfaction in their role, thus being more likely to support students' learning and exhibit greater commitment. The role of the principal has also been highlighted. Moving forward, we must determine methods to ensure that principals are able to support teachers as effectively as possible whilst recognising the many responsibilities and activities they must complete on a daily basis.

Teachers' development is an ongoing duty, embedded in the roles of both teachers and principals as educators, rather 
than a standalone programme or activity. Teachers must be accountable for their own development and must look to principals for guidance without depending on them completely. Today, teachers must take the opportunity to take a more active, vocal role in how their own development is designed and delivered to them if they are to step out of the traditionally passive position that strips them of empowerment, creativity and growth. However, this can be overwhelming for teachers, and therefore principals must step forward to ensure that teachers are supported in gaining confidence, leadership skills and decision-making abilities that will help them to learn and develop autonomously, thus enabling them to encourage the same in their students.

\section{REFERENCES}

[1] A. Craft, Continuing Professional Development: A practical guide for teachers and schools. London, Routledge Falmer, 2000

[2] J. Harland and K. Kinder, "Teachers' Continuing Professional Development: framing a model of outcomes," British Journal of Inservice Education, vol. 23, no. 1, pp. 71 - 84, 1997.

[3] A. Harris, "Leadership in Schools Facing Challenging Circumstances, International Congress of School Effectiveness and School Improvement," Copenhagen, 2002.

[4] C. Day, Developing Teachers: The Challenges of Lifelong Learning. London: Falmer Press, 1999 .

[5] A. Hargreaves, Changing teachers, changing times: teachers' work and culture in the postmodern age. London: Cassell, 1994.

[6] B.E. Joyce, and Calhoun, Models of Teaching: Tools For Learning. Buckingham: Open University Press, 1998

[7] J.E. Talbert and M.W. McLaughlin, "Teacher professionalism in local school contexts," American journal of education, vol. 102, no. 2, pp. 123-153, 1994.

[8] M. Maden and J. Hillman, Success Against the Odds. London: Routledge, 1996.

[9] J. Gray, Causing Concern but Improving: A Review of Schools Experience. London, DfEE, 2000.

[10] OFSTED, Improving City Schools. London: Offfice for Standards in Education, 2000.

[11] C. Day, "Professional development and reflective practice: purposes, processes and partnerships," Pedagogy, Culture and Society, vol. 7, no. 2, pp. $221-233,1999$.

[12] J. W. Little, "Teachers' Professional Development in a Climate of Educational Reform. NCREST Reprint Series.," 1993.

[13] R. Bolam, "Emerging policy trends: some implications for continuing professional development," J. in-service Educ., vol. 26, no. 2, pp. 267$280,2000$.

[14] F. Coffield, "Introduction: A critical analysis of the concept of a learning society," Differing visions a Learn. Soc., vol. 1, 2000.

[15] A. Friedman and M. Phillips, "Continuing professional development: Developing a vision,” J. Educ. Work, vol. 17, no. 3, pp. 361-376, 2004.

[16] A. Friedman, C. Durkin, and M. Phillips, "CPD: what are the true costs of continuing professional development?," Contin. Prof. Dev., vol. 3, no. 3 , pp. 78-87, 2000.

[17] H. Tomlinson, Educational leadership: Personal growth for professional development, vol. 3. Sage, 2004.

[18] C. Rapkins, "Best practice for continuing professional development: professional bodies facing the challenge," Contin. Prof. Dev. Issues Des. Deliv.,pp. 216-225, 1996.
[19] T. Kennie, "THE GROWING IMPORTANCE OF CPD-puts the case for understanding that CPD is simply a part of good professional practice," Logist. Transp. Focus, vol. 3, no. 3, pp. 51-54, 2001

[20] G. Guest, "Lifelong Learning for the Global Networked Society.," 2000.

[21] D. Mujis, C. Day, A. Harris, and G. Lindsay, "Evaluating continuing professional development: An overview." International handbook on the continuing professional development of ..., 2004.

[22] C. L. Smith and R. L. Freeman, "Using continuous system level assessment to build school capacity," Am. J. Eval., vol. 23, no. 3, pp. 307-319, 2002.

[23] P. Knight, "A systemic approach to professional development: learning as practice," Teach. Teach. Educ., vol. 18, no. 3, pp. 229-241, 2002.

[24] S. Edmonds and B. Lee, "Teacher feelings about continuing professional development,” Educ. J., vol. 61, no. 1, pp. 28-29, 2002.

[25] M. McAteer, R. Foster, J. Groves, F. Hallet, M. Jones, and T. Rutter "Continuing professional development: Exploring the impact on teachers' professional practice and pupil learning," in BERA annual conference, University of Glamorgan, 2005, pp. 14-17.

[26] P. Cordingley, M. Bell, S. Thomason, and A. Firth, "The impact of collaborative continuing professional development (CPD) on classroom teaching and learning," Rev. How do Collab. Sustain. CPD Sustain. but not Collab. CPD Affect Teach. Learn., 2005.

[27] B. Joyce, "Improving inservice training: The messages of research," Educ. Leadersh., vol. 37, pp. 379-385, 1980

[28] T. R. Guskey, Evaluating professional development. Corwin press, 2000

[29] P. Cordingley, M. Bell, B. Rundell, and D. Evans, "The impact of collaborative CPD on classroom teaching and learning. Research evidence in education library," in Evidence for policy and practice information and co-ordinating centre (EPPI-centre): Social science research unit, institute of education, University of London London, 2003

[30] P. Cordingley, M. Bell, D. Evans, and A. Firth, "The impact of collaborative CPD on classroom teaching and learning. Review: What do teacher impact data tell us about collaborative CPD,” Res. Evid. Educ. Libr., 2005.

[31] H. Burchell, J. Dyson, and M. Rees, "Making a difference: a study of the impact of continuing professional development on professional practice," J. in-service Educ., vol. 28, no. 2, pp. 219-230, 2002.

[32] S. Lyle, "An investigation into the impact of a continuing professional development programme designed to support the development of teachers as researchers in South Wales," J. In-Service Educ., vol. 29, no. 2, pp. 295-314, 2003

[33] C. Robinson and J. Sebba, "A review of research and evaluation to inform the development of the new postgraduate professional development programme," TTA/University of Sussex, 2004

[34] P. V Bredeson, "The school principal's role in teacher professional development," J. in-service Educ., vol. 26, no. 2, pp. 385-401, 2000

[35] B. R. Joyce and B. Showers, "Student achievement through staff development," 2002

[36] P. V Bredeson, "Communications as a measure of leadership in schools: A portraiture of school principals," high Sch. J., vol. 71, no. 4, pp. 178$186,1988$.

[37] P. C. Gronn, "Talk as the work: The accomplishment of school administration," Adm. Sci. Q., pp. 1-21, 1983.

[38] A. W. Hart and P. V Bredeson, The principalship: A theory of professional learning and practice. McGraw-Hill Humanities, Social Sciences \& World Languages, 1996

[39] P. V Bredeson, "Negotiated Learning: unions contracts and teache professional development. paper presented at the Annual Meeting of the American Educational Research Association in Montreal, 20 April.” Canada, 1999. 
[40] N. Bennett and B. Smith, "Assessing the impact of professional development in educational leadership and management: the IMPPEL project," Manag. Educ., vol. 14, no. 2, pp. 25-27, 2000.

[41] K. W. Eastwood and K. S. Louis, "Restructuring that lasts: Managing the performance dip," J. Sch. Leadersh., vol. 2, no. 2, pp. 212-224, 1992.

[42] B. Showers and B. Joyce, "The evolution of peer coaching," Educ. Leadersh., vol. 53, pp. 12-16, 1996.

[43] D. Hopkins and A. Harris, Creating the conditions for teaching and learning: A handbook of staff development activities. Routledge, 2013.
[44] D. Muijs and G. Lindsay, "Where are we at? An empirical study of levels and methods of evaluating continuing professional development," Br. Educ. Res. J., vol. 34, no. 2, pp. 195-211, 2008.

[45] N. Jones and N. Fear, "Continuing professional development: perspectives from human resource professionals," Pers. Rev., 1994.

[46] C. Day, "Quality assurance and professional development," J. In-Service Educ., vol. 17, no. 3, pp. 189-194, 1991.

[47] T. R. Guskey, "Professional development in education: in search of the optimal mix.," 1994.. 